\title{
Long Term Follow-Up of Persistent Outer Retinal Defects following Macular Hole Surgery
}

\author{
Mehrdad M, Akshay ST, Justin W, Steven TB, Dongseok C and Christina JF* \\ ${ }^{*}$ Casey Eye Institute, Oregon Health and Science University, USA
}

Submission: March 19, 2017; Published: June 05, 2017

*Corresponding author: Christina JF, Casey Eye Institute, Oregon Health \& Science University, USA, Tel: (503)-494-7891; Fax: (503)-494-7233;

Email: flaxelc@ohsu.edu

Abstract

Purpose: To describe a case series of persistent outer retinal defects following successful macular hole closure with vitrectomy.

Design: Retrospective case series.

Methods: Retrospective case series reviewing medical records of adults undergoing pars plana vitrectomy (PPV) for repair of stage 2 to 4 idiopathic macular holes from 2006 through 2009 at Casey Eye and Devers Eye Institute. Spectral domain optical coherence tomography (OCT) in follow-up was reviewed.

Results: Of 43 eyes that had successful surgery with macular hole closure, 11 cases (25.5\%) presented with persistent outer retinal defects on OCT at least three months after surgery (nine females, two males, mean age $66.8 \pm 8.2$ years). Mean follow up time was $60.5 \pm 43.2$ months, (ranging 3 to 118). Of these eleven cases, four had short follow up time (up to one year), during which the outer retinal defect persisted in three and macular hole re-opened in one. Seven eyes had longer follow-up with a minimum of 6 years (mean 89.8 \pm 18.6 months, ranging 72 to 118 ). Of these eyes, three $(42.8 \%)$ developed spontaneous late closure of the outer defects. All three had improved visual acuity after the outer defect was closed (from average 20/50 to 20/25).

Conclusion: In this small study, a quarter of patients recovering from macularhole surgery had persistent postoperative outer retinal defects at one year. About $42.8 \%$ of these defects improved spontaneously over time with improved visual acuity in all cases that the defect closed. Further larger studies are needed to investigate such changes.

Keywords: Macular hole surgery; Outer retinal defect; Vitrectomy

\section{Introduction}

Pars plana vitrectomy, peeling of internal limiting membrane and gas tamponade is currently the standard treatment for macular hole with high success rate and generally favorable visual outcomes. Previous studies have indicated that a significant number of surgically repaired macular hole patients may have persistent outer retinal defects (microholes) detected with OCT. These are associated with lower best corrected visual acuity (BCVA) following surgery [1-4]. Previous studies have also reported that such outer retinal defects represent discontinuities in the ellipsoid zone (EZ) and the external limiting membrane (ELM) and that there was increased normalization of the EZ and ELM over the first 12 months of post-op follow-up associated with improved visual acuity [5-6]. The purpose of this study is to report a series of such cases with long (greater than 1 year) follow up.

\section{Methods}

Retrospective case series reviewing medical records of adults undergoing pars plana vitrectomy (PPV) and gas tamponade for repair of stage 2 to 4 idiopathic macular holes from 2006 through 2009 at Casey Eye Institute and Devers Eye Institute was performed. Peeling of internal limiting membrane (ILM) was not performed in any of the cases. Demographic data, visual acuity, clinical course and optical coherence tomography (OCT) in post-surgical follow-up visits were reviewed and recorded. Time domain (TD) Stratus OCT was available and performed in the early postoperative period followed by spectral domain (SD) OCT in the later follow up visits. The study was approved by the institutional review board at Oregon Health and Science University and was conducted in accordance with the Helsinki Declaration.

\section{Results}

During the study period, 80 eyes of 73 patients ( 25 males and 58 females, mean patient age 67.4 years) with idiopathic macular holes underwent macular hole surgery with standard pars plana vitrectomy without Internal limiting membrane peeling, gas tamponade with either short-acting non-expansile 


\section{JOJ Ophthalmology}

concentrations of sulfur hexafluoride (SF6) or longer-acting non-expansile perfluoropropane (C3F8) or hexafluoroethane (C2F6). Macular hole closure was achieved in 61 eyes (76.3\%). Post-operative OCT data was available in 43 of these eyes (70\%). Of these 43 eyes, 11 cases (25.5\%) presented with persistent outer retinal defects on OCT at least three months after surgery. The group consisted of nine females and two males with mean age of $66.8 \pm 8.2$ years at the time of surgery. Analysis of right versus left eye and short versus long-acting gas tamponade failed to show any statistically significant difference among eyes who had persistent outer retinal defect.

Mean follow up time of these 11 cases was $60.5 \pm 43.2$ months, with a range of 3 to 118 months. Of these eleven cases, three had less than one year of follow up due to death (one) or decision not to follow up further (two), during which time the outer retinal defect persisted in all three. Another patient had a re-opened macular hole at approximately a year after surgery but did not undergo further treatment. Seven eyes had longer follow-up with a minimum of 6 years (mean $89.8 \pm 18.6$ months, ranging 72 to 118 ) (Table 1). Of these eyes, three (42.8\%) developed spontaneous late closure of the outer retinal defects (Figure 1). All three had improved visual acuity after the outer defect was closed (from average 20/50 to 20/25). The final visual acuity in patients without a persistent outer retinal defect at the last follow-up was better than those with a defect, but the difference was not statistically significant due to small sample size.

Table 1: Summary of cases with persistent outer retinal defect at 3 months follow up detected by Time Domain (TD) OCT. F: Female; M: Male; OD:

\begin{tabular}{|c|c|c|c|c|c|c|c|c|c|}
\hline Case & Age & Sex & $\begin{array}{l}\text { Year of } \\
\text { Surgery }\end{array}$ & Eye & $\begin{array}{c}\text { Visual Acuity at } \\
3 \text { month Follow } \\
\text { up (Log MAR) }\end{array}$ & $\begin{array}{c}\text { Total } \\
\text { Follow up } \\
\text { (months) }\end{array}$ & $\begin{array}{c}\text { Visual Acuity at } \\
\text { Final Follow up } \\
\text { (Log MAR) }\end{array}$ & $\begin{array}{c}\text { OCT Type at } \\
\text { Final Follow } \\
\text { up }\end{array}$ & $\begin{array}{c}\text { Final outcome } \\
\text { of Outer retinal } \\
\text { Defect }\end{array}$ \\
\hline 1 & 60 & $\mathrm{~F}$ & 2007 & OS & 0.3 & 95 & 0.1 & SD & Sealed \\
\hline 2 & 59 & $\mathrm{~F}$ & 2009 & OD & 0.7 & 82 & 0.1 & SD & Persistent \\
\hline 3 & 69 & $\mathrm{~F}$ & 2009 & os & 0.5 & 79 & 0.4 & SD & Persistent \\
\hline 4 & 82 & M & 2008 & OD & 0.4 & 8 & 0.4 & $\mathrm{TD}$ & Deceased \\
\hline 5 & 53 & $\mathrm{~F}$ & 2003 & OS & 0.5 & 118 & 0.2 & SD & Persistent \\
\hline 6 & 69 & $\mathrm{~F}$ & 2009 & OD & 0.3 & 72 & 0.5 & SD & Persistent \\
\hline 7 & 67 & $\mathrm{~F}$ & 2008 & OD & 0.3 & 72 & 0.2 & SD & Sealed \\
\hline 8 & 68 & $\mathrm{~F}$ & 2009 & OD & 0.1 & 16 & 1 & $\mathrm{TD}$ & Reopen \\
\hline 9 & 69 & $\mathrm{~F}$ & 2006 & OS & 0.4 & 111 & 0.1 & SD & Sealed \\
\hline 10 & 77 & M & 2009 & OD & 0.2 & 3 & 0.2 & $\mathrm{TD}$ & Lost to follow \\
\hline 11 & 62 & $\mathrm{~F}$ & 2006 & os & 0.4 & 10 & 0.4 & $\mathrm{TD}$ & Lost to follow \\
\hline
\end{tabular}
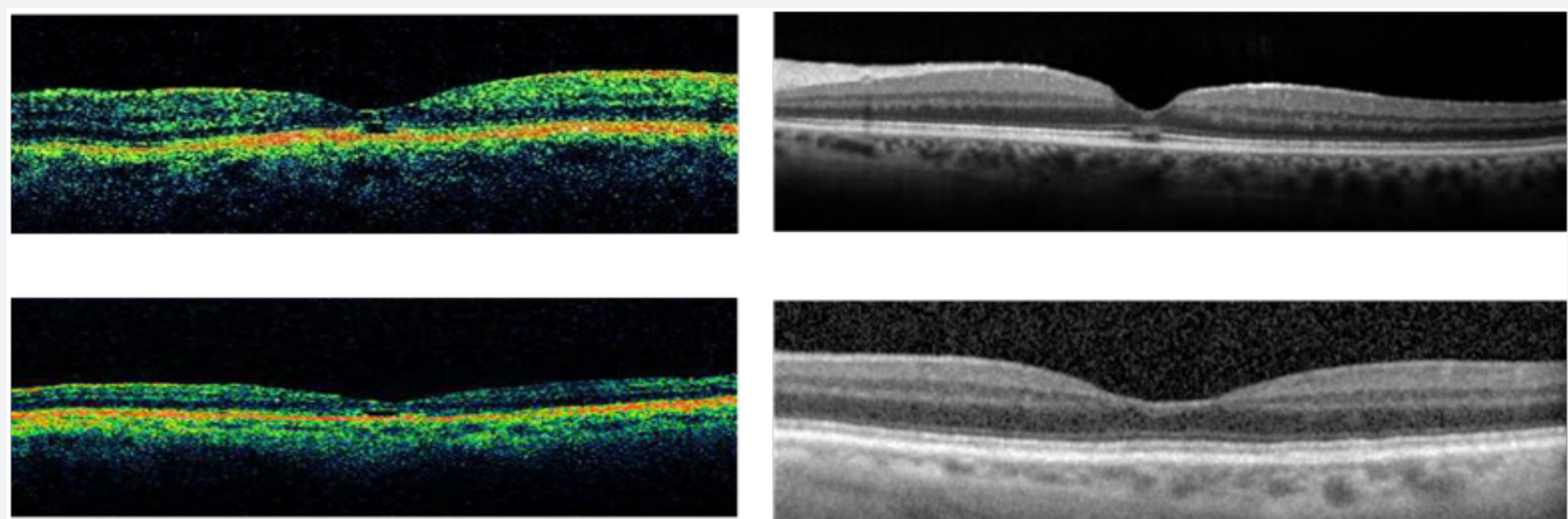

Figure 1: Top Left: Time Domain OCT 3 months post-operative of one of the subjects reveals outer retinal defect and IS/OS disruption. Top right: SD OCT 7 years post-operative with remaining defect. Bottom Left: Stratus OCT 12 months post-operative of another subject with similar findings resolved in a Spectral domain OCT about 6 years after surgery (Bottom Right). 


\section{Discussion}

In our study, the overall rate of macular hole closure after single primary PPV was similar to previously contemporaneous reported closure rates using the same technique without ILM peeling [7-14]. Of note, the routine ILM peel and other advances have increased the anatomical success rate of MH surgery to more than $90 \%$ hole closure. Successful macular hole closure after surgery is determined clinically by bio microscopy and a negative Watzke-Allen test and is often verified with OCT. Several previous studies have evaluated ultra structural OCT imaging of the foveal region in an attempt to correlate this anatomy with visual outcomes and have suggested that outer retinal features are more important than inner retinal features in determining visual acuity [1,2,15-18]. Several studies have reported similar rates of outer retinal defects following successful macular hole surgery $[1,2,17,18]$. Histopathologic examination of eyes after macular hole surgery has demonstrated that hole closure start by re-approximation of the edges of the hole to the retinal pigment epithelium followed by growth of Müller cells and astrocytes into the hole to fill in the photoreceptor cell layer [19-24]. This is followed by circumferential and radial contraction of the glial plug pulling the photoreceptor cell layer toward the center of the hole. During this process, there is a potential for anterior displacement of tissue and therefore the presence of a space between migrating glial and photoreceptor cells from the retinal pigment epithelium in the central area. This can be viewed in OCT as persistent outer layer defect and can be seen as focal foveal detachment, ellipsoid zone disruption or both. Other possible explanations for such defects include outer retina (Müller cells/ photoreceptor or RPE) damage from long standing macular hole or surgical trauma during vitrectomy. These defects can also be associated with decreased visual acuity, although case reports of outer retinal defects with good visual acuity are present in the literature $[15,19]$. Further migration of the glial cell (and/ or photoreceptors) and their adherence to the retinal pigment epithelium centrally is probably responsible for healing of such defects and disappearance of the central OCT defect.

To our knowledge, no other study has investigated the long term outcome (to the extent of average 60 months post operatively) of such defects after successful macular hole surgery. A variety of lesions with similar morphology have been described and referred to as macular microholes [25]. They are small lamellar defects in the outer retina or retinal pigment epithelium that occur through a variety of mechanisms, including spontaneous vitre oretinal interface changes, trauma, photo toxicity, abortive macular hole formation and other unrecognized causes. The condition is non progressive, occurs in patients of all ages, and is compatible with good visual acuity. The retinal changes described in our study can provide a presumptive patho physiological mechanism and natural course for such lesions as well. In our study, we observed that a significant percentage of the outer retinal defects may heal after a long period of follow up. Although we noticed that such healing can be associated with improved visual acuity, such observations are very few in number and also may have been confounded by other factors in the long follow up interval. Therefore, further studies need to be performed to determine whether such observed changes in the visual acuity is truly related to healing of the outer retinal defect. Major limitations of our study include being retrospective and of relatively small size. Surgeries were performed by several surgeons and methods. The low resolution of Stratus images should be recognized as a limitation, particularly since the premise of the study is to identify subtle outer retinal defects. Also, 25\% of closed macular holes were lost to follow-up in our center potentially causing significant follow-up bias. There was a long gap between the early follow up and the late follow up of many subjects which confounded the interpretation of interval changes in visual acuity. Similar studies with a larger number of patients and more frequent and regular follow up evaluation are needed to further investigate these lesions. And their final outcome.

\section{Conclusion}

In this study, a quarter of patients recovering from macular hole surgery had persistent postoperative outer retinal defects at one year. About42.8\%of these defects improved spontaneously over time. Visual acuity may improve if the defect closes, although further studies are needed to investigate such changes.

\section{Financial Disclosure}

This research is supported by grant P30 EY010572 from the National Institutes of Health (Bethesda, MD), and by unrestricted departmental funding to the Casey Eye Institute from Research to Prevent Blindness (New York, NY).

\section{References}

1. Sano M, Shimoda Y, Hashimoto H, Kishi S (2009) Restored photoreceptor outer segment and visual recovery after macular hole closure. Am J Ophthalmol 147(2): 313-318.

2. Chawla A, Barua A, Patton N (2016) Long Term Structural and Functional Outcomes after Macular Hole Surgery. Retina 36(2): 321324.

3. Itoh Y, Inoue M, Rii T, Hiraoka T, Hirakata A (2012) Correlation between Length of Foveal Cone Outer Segment Tips Line Defect and Visual Acuity after Macular Hole Closure. Ophthalmology 119(7): 1438-1446.

4. Oh J, Smiddy WE, Flynn HW, Gregori G, Lujan B (2010) Photoreceptor Inner/Outer Segment Defect Imaging by Spectral Domain OCT and Visual Prognosis after Macular Hole Surgery. Invest Ophthalmol Vis Sci 51(3): 1651-1658.

5. Oh J, Yang SM, Choi YM, Kim SW, Huh K (2013) Glial proliferation after vitrectomy for a macular hole: a spectral domain optical coherence tomography study. Graefes Arch Clin Exp Ophthalmol 251(2): 477-484.

6. Chang YC, Lin WN, Chen KJ, Wu HJ, Lee CL, et al. (2015) Correlation between the Dynamic Postoperative Visual Outcome and the Restoration of Foveal Microstructures After Macular Hole Surgery. Am J Ophthalmol 160(1): 100-106.

7. Carvounis PE, Kopel AC, Kuhl DP, Heffez J, Pepple K, et al. (2008) 25gauge vitrectomy using sulfur hexafluoride and no prone positioning for repair of macular holes. Retina 28(9): 1188-1192. 
8. Isomae T, Sato Y, Shimada H (2002) Shortening the duration of prone positioning after macular hole surgery-comparison between 1-week and 1-day prone positioning. Jpn J Ophthalmol 46(1): 84-88.

9. Krohn J (2005) Duration of face-down positioning after macular hole surgery: a comparison between 1 week and 3 days. Acta Ophthalmol Scand 83(3): 289-292.

10. Sato Y, Isomae T (2003) Macular hole surgery with internal limiting membrane removal, air tamponade, and 1-day prone positioning. Jpn J Ophthalmol 47(5): 503-506.

11. Wickens JC, Shah GK (2006) Outcomes of macular hole surgery and shortened face down positioning. Retina 26(8): 902-904.

12. Schaal S, Barr CC (2009) Management of macular holes: a comparison of 1-year outcomes of 3 surgical techniques. Retina 29(8): 1091-1096.

13. Haritoglou C, Reiniger IW, Schaumberger M, Gass CA, Priglinger SG, et al. (2006) Five-year follow-up of macular hole surgery with peeling of the internal limiting membrane: update of a prospective study. Retina 26(8): 618-622.

14. Passemard M, Yakoubi Y, Muselier A, Hubert I, Guillaubey A, et al (2010) Long-term outcome of idiopathic macular hole surgery. Am J Ophthalmol 149(1): 120-126.

15. Villate N, Lee JE, Venkatraman A, Smiddy WE (2005) Photoreceptor layer features in eyes with closed macular holes: optical coherence tomography findings and correlation with visual outcomes. Am JOphthalmol 139(2): 280-289.

16. Mirza RG, Johnson MW, Jampol LM (2007) Optical coherence tomography use in evaluation of the vitreoretinal interface: a review. Surv Ophthalmol 52(4): 397-421.
17. Ko TH, Witkin AJ, Fujimoto JG, Chan A, Rogers AH, et al. (2006) Ultrahigh-resolution optical coherence tomography of surgically closed macular holes. Arch Ophthalmol 124(6): 827-836.

18. Mahmoud TH, McCuen BW (2007) Natural history of foveolar lucencies observed by optical coherence tomography after macular hole surgery. Retina Jan 27(1): 95-100.

19. Moshfeghi AA, Flynn HW, Elner SG, Pulitafito CA, Gass JDM (2005) Persistent outer retinal defect after successful macular hole repair. Am J Ophthalmol 139(1): 183-184.

20. Funata M, Wendel RT, de la Cruz Z, Green WR (1992) Clinicopathologic study of bilateral macular holes treated with pars plana vitrectomy and gas tamponade. Retina 12(4): 289-298.

21. Madreperla SA, Geiger GL, Funata M, de la Cruz Z, Green WR (1994) Clinicopathologic correlation of a macular hole treated by cortical vitreous peeling and gas tamponade. Ophthalmology 101(4): 682-686.

22. Ip MS, Baker BJ, Duker JS, Reichel E, Baumal CR, et al. (2002) Anatomical outcomes ofsurgery for idiopathic macular hole as determined by opticalcoherence tomography. Arch Ophthalmol 120(1): 29-35.

23. Rosa RH, Glaser BM, de la Cruz Z, Green WR (1996) Clinicopathologiccorrelation of an untreated macular hole and amacular hole treated by vitrectomy, transforming growthfactor-beta 2, and gas tamponade. Am J Ophthalmol 122(6): 853-863.

24. Gass JD (1995) Reappraisal of biomicroscopic classification of stagesof development of a macular hole. Am J Ophthalmol 119(6): 752-759.

25. Emerson GG, Spencer GR, Klein ML (2007) Macular microholes. Retina 27(5): 595-600.

\section{Your next submission with Juniper Publishers} will reach you the below assets

- Quality Editorial service

- Swift Peer Review

- Reprints availability

- E-prints Service

- Manuscript Podcast for convenient understanding

- Global attainment for your research

- Manuscript accessibility in different formats

(Pdf, E-pub, Full Text, Audio)

- Unceasing customer service

Track the below URL for one-step submission https://juniperpublishers.com/online-submission.php 